\title{
Antisense Knockdown of the Shaker-like KvI.I Gene Abolishes the Central Stimulatory Effects of Amphetamines in Mice and Rats
}

\author{
Carla Ghelardini', Alessandro Quattrone' ${ }^{2}$, Nicoletta Galeotti', Silvia Livi ${ }^{3}$, Grazia Banchelli', Laura \\ Raimondi' and Renato Pirisino*,' \\ 'Department of Preclinical and Clinical Pharmacology, University of Florence Viale Pieraccini, Florence, Italy; ${ }^{2}$ Servizio di Genetica Medica, \\ Ospedale Casa Sollievo della Sofferenza, Foggia, Italy; ${ }^{3}$ Department of Pharmacology, University of La Sapienza, Rome, Italy
}

\begin{abstract}
Amphetamine (AMPH) is an indirect sympathomimetic compound classified as a substrate-type releaser that distinguishes it from other stimulants that act as uptake I blockers, such as cocaine (COC). In mammals, AMPH elicits central stimulation, hypermotility, anorexia, analgesia and analeptic activity, mainly through the increase of extracellular brain dopamine (DA). The inversion of vesicular transporters and/or intravesicular alkalinization is assumed to have a role in AMPH-induced exocytosis. However, the action mechanism of this compound has not yet been completely clarified. Recent evidence on the action of AMPHs indicates potassium channel-blocking properties in peripheral tissues. We investigated the possible involvement of a Shaker-like KvI.I channel subtype in the central effects of $\mathrm{AMPH}$, using an antisense oligodeoxyribonucleotide (aODN) that specifically and reversibly inhibits the expression of these channels in the brain. The effect of aODN pretreatments was studied by evaluating the modification of behavioral effects induced in mice through the intracerebroventricular administration of $\mathrm{AMPH}, \mathrm{COC}$, or other compounds. The aODN in mice almost completely blocked the stimulatory effects of $\mathrm{AMPH}$ and other releasers but was ineffective in reducing the central activity of COC. In aODN-pretreated rats a strong reduction of the $\mathrm{AMPH}$, but not of the COC-stimulated DA efflux from nucleus accumbens was observed. Our results suggest that the stimulant effects of $\mathrm{AMPH}$ and chemically related compounds, but not COC, require the presence of functionally active KvI.I channels in the brain.
\end{abstract}

Neuropsychopharmacology (2003) 28, 1096-I I05, advance online publication, 9 April 2003; doi: I 0.I038/sj.npp. I 300162

Keywords: amphetamine; cocaine; antisense oligodeoxyribonucleotides; Kvl.I channels; dopamine; behavioral functions

\section{INTRODUCTION}

The sympathomimetic compound amphetamine (AMPH), which readily crosses the blood-brain barrier, induces considerable central stimulatory effects, including euphoria, insomnia, anorexia, stimulation of motility, etc (Hoffman, 2001). Neurochemical evidence indicates that, in mammals, this compound has its effects indirectly, mainly increasing the extracellular availability of dopamine (DA), in different brain regions (Samanin and Garattini, 1993). For example, dopaminergic neuronal endings located in the nucleus accumbens are important targets for the motor stimulatory effects (Kalivas et al, 1993), while the perifornical area seems to be the region in which AMPH and other

* Correspondence: R. Pirisino, Dipartimento di Farmacologia Preclinica e Clinica, Viale Pieraccini 6, 50134 Florence, Italy, Tel: +39055 427|209, Fax: +39055 427/280, E-mail: renato.pirisino@unifi.it

Received 20 September 2002; revised 19 November 2002; accepted 23 December 2002

Online publication: 14 January 2003 at http://www.acnp.org/citations/ Npp0। I 403459 dopaminergic compounds selectively control food intake (Parada et al, 1988; Leibowitz, 1989). Together with DA, serotonin $(5-\mathrm{HT})$ is known to have a central role in most behavioral functions (Parada et al, 1988; Inui, 2000; Frantz et al, 2002). Food intake is controlled by serotoninergic neurons projecting from the midbrain dorsal raphe nucleus to PVN and the VM of the hypothalamus. In these areas, AMPH and, to a major extent, the more selective compound dexfenfluramine (d-FEN), act as an anorexigenic, also increasing the extracellular concentrations of 5-HT (Leibowitz, 1989; Simansky, 1996).

Indirectly acting dopaminergic and/or serotoninergic compounds can be divided into two main classes relative to their mechanism of action. Some of them, such as cocaine (COC) or fluoxetine, are inhibitors of the uptake 1 mechanisms in neurons. For others, including AMPH and related phenylethylamines, the action mechanism has not yet been completely clarified. Since their effects are reduced after COC and reserpine pretreatment or chronic postganglionic denervation, it is generally accepted that, following the uptake into nerve endings, they displace the 
neurotransmitters from the storage vesicles, by means of various mechanisms (Sulzer and Rayport, 1990; Sulzer et al, 1995).

The potassium channel activity, influencing the transmembrane electrochemical potential of neurons, may also affect the central release of DA, 5-HT, and other neurotransmitters (Cook and Quast, 1990; Dawson and Routledge, 1995). Outward potassium channels, opened by depolarisation, shorten the duration of the action potential (delayed rectifier) or the pattern of action potential bursts (transient or A current). Pharmacological opening of these channels displays hyperpolarizing activity, while the blockade prolongs the duration of the action potential, thus enhancing the release of neurotransmitters (Schechter, 1997). In accordance with the properties of these compounds, $\mathrm{K}_{\mathrm{ATP}}$ openers, injected intracerebroventricular (i.c.v.) in mice, increase food intake, whereas $\mathrm{K}^{+}$channel blockers induce hypophagic effects. The role of potassium channels in behavioral function has been investigated using an antisense strategy. It was found that the repeated i.c.v. administration of an antisense oligodeoxyribonucleotide (aODN) targeting the translation start region of Shaker-like Kv1.1 potassium channels induces hyperphagic behaviour, together with a transient-specific reduction in the expression of this channel subtype in the mouse brain (Ghelardini et al, 1997).

In preliminary experiments, we used this aODN to investigate the mechanism of action of some hypophagic compounds believed to elicit their anorectic effects through a potassium channel modulation. It has been found that the aODN pretreatment decreased the hypophagic effect of certain compounds known to act as blockers of voltageactivated potassium channels and, more interesting, of $\mathrm{AMPH}$, used as a reference anorectic compound in these studies (Banchelli et al, 2001; Pirisino et al, 2001). These results opened up the possibility that, in addition to its anorectic effects, the whole range of central stimulant properties of AMPH could be linked to the blocking properties of specific potassium channels.

The present work was therefore designed to better evaluate the involvement of Kv1.1 channel subtypes in the central effects of AMPH using a battery of tests that are able to evaluate analeptic activity, pain perception, motor activity, food intake, and other behavioral functions. In these experiments, the activity of COC, d-FEN and other indirectly acting dopaminergic and serotoninergic compounds was evaluated, for reference, in mice pretreated with specific aODN.

\section{MATERIALS AND METHODS}

\section{Animals}

Male Swiss albino mice (24-26g) and albino rats (150$200 \mathrm{~g}$ ) from Morini (San Polo d'Enza, Italy) were used. In all, 15 mice or five rats were housed per cage. The cages were placed in the experimental room $24 \mathrm{~h}$ before the test for acclimatization purposes. The animals were fed a standard laboratory diet and tap water ad libitum; they were kept at $23 \pm 1{ }^{\circ} \mathrm{C}$, with a $12 \mathrm{~h}$ light/dark cycle, and light at $7 \mathrm{am}$. All experiments were carried out in accordance with the European Community Council's Directive of
November 24, 1986 (86/609/EEC) relative to experimental animal care. All efforts were made to minimize animal suffering and to reduce the number of animals used (in any case, since otherwise indicated, at least 10 animals per group were used in each behavioral protocol).

\section{Hot-Plate Test}

The method adopted was described by O'Callaghan and Holtzman (1975). Mice were placed inside a stainless-steel container that was set thermostatically at $52.5 \pm 0.1^{\circ} \mathrm{C}$, in a precision water bath from the KW Mechanical Workshop, Siena, Italy. Reaction times (s) were measured with a stopwatch before, and 15,30 , and $45 \mathrm{~min}$ after administration of the analgesic drugs. The end point used was the licking of the fore or hind paws. Those mice scoring less than 12 and more than $18 \mathrm{~s}$ in the pretest were rejected (30\%). An arbitrary cutoff time of $45 \mathrm{~s}$ was adopted.

\section{Hole-Board Test}

The hole-board test consisted of a $40 \mathrm{~cm}$ square plane with 16 flush-mounted cylindrical holes $(3 \mathrm{~cm}$ diameter $)$ distributed $4 \times 4$ in an equidistant, grid-like manner. Mice were placed on the center of the board one by one and allowed to move about freely for a period of $10 \mathrm{~min}$ each. Two electric eyes crossing the plane from midpoint to midpoint of opposite sides, thus dividing the plane into four equal quadrants, automatically signalled the movement of the animal (counts $/ 5 \mathrm{~min}$ ) on the surface of the plane (locomotor activity). Miniature photoelectric cells in each of the 16 holes recorded (counts $/ 5 \mathrm{~min}$ ) exploration of the holes (exploratory activity) by the mice. In each group, 1215 mice were tested.

\section{Pentobarbital-Induced Sedative/Hypnotic Effects}

The method was described by Adzu et al (2002). Mice received $5 \mu$ i.c.v. injections of test compounds, or saline in the control group. Sodium pentobarbital $(25 \mathrm{mg} / \mathrm{kg})$ was administered i.p. to the animals $15 \mathrm{~min}$ after they received saline or the test compounds. The time that elapsed between the administration of pentobarbital until loss of the righting reflex was recorded as the onset of sleep, while the time from the loss of the righting reflex (in which the mouse cannot roll back when turned over) until recovery was recorded as the sleeping time.

\section{Drug Administration by i.c.v. Route}

The i.c.v. administration was performed under ether anesthesia with isotonic saline used as solvent, according to the method described by Haley and Mccormick (1957). During anesthesia, the mice were grasped firmly by the loose skin behind the head. A hypodermic needle $(0.4 \mathrm{~mm}$ external diameter) attached to a $10 \mu \mathrm{l}$ syringe was inserted perpendicularly through the skull and no more than $2 \mathrm{~mm}$ into the brain of the mouse, where a $5 \mu$ l solution was then administered. The injection site was $1 \mathrm{~mm}$ to the right or left of the midpoint on a line drawn through to the anterior base of the ears. Injections were performed randomly into the right or left ventricle. To ascertain that solutions were 
administered exactly into the cerebral ventricle, some mice were injected with $5 \mu \mathrm{l}$ of diluted 1:10 India ink and their brains were examined macroscopically after sectioning. The accuracy of the injection technique was evaluated, with $95 \%$ of injections being correct. Before i.c.v. administration of the compounds used, it was assessed that the $\mathrm{pH}$ values of the nanomolar compound solutions, ranging from 7.2 to 6.7, did not vary significantly from those of the saline $(\mathrm{pH}=6.8 \pm 0.4)$.

\section{Evaluation of Food Consumption}

The mice did not have access to food for $12 \mathrm{~h}$, but water was available ad libitum. A weighed amount of food (standard laboratory pellets) was given, and the amount consumed (evaluated as the difference between the original amount and the food left in the cage, including spillage) was measured 15, 30, 45, and $60 \mathrm{~min}$ after i.c.v. or i.p. administration of saline or drug solutions, with an accuracy of $0.1 \mathrm{~g}$. An arbitrary cutoff time of $60 \mathrm{~min}$ was used, and the total amount of food consumed was expressed in $\mathrm{mg} /$ mouse/60 min.

\section{Antisense Oligonucleotides}

24mer phosphodiester oligonucleotides (ODNs) were capped by a terminal phosphorothioate double substitution and purified by high-performance liquid chromatography (HPLC; Genosys, The Woodlands, TX, USA). The antisense oligonucleotide (aODN) (5'-CGA CAT CAC CGT CAT GAT GAA AGG- $3^{\prime}$ ) was designed by targeting the $5^{\prime}$ portion of the murine Kv1.1 mRNA, residues 575-598 of the published cDNA sequence (Chandy et al, 1990).

The corresponding aODN sequence for rat (5'-TGA CAT CAC CGT CAT GAT GGA TGC-3'), encoding for mRNA to the Kv1.1 channel, was the same as used in previous studies (Meiri et al, 1997). To evaluate the specific antisense effects of the oligodeoxynucleotides, a fully degenerated phosphorodiester phosphorothioate-capped oligonucleotide (dODN) was used as negative control. The fully degenerated $24 \mathrm{mer}$ is a collection of about $3 \times 10^{14}$ different molecular species $\left(5^{\prime}-\right.$ NNN NNN NNN NNN NNN NNN NNN NNN-3'; where $N=\mathrm{G}$, $\mathrm{C}, \mathrm{A}$, or $\mathrm{T}$ ). Therefore, for the nanomolar-micromolar range concentrations used in the antisense experiments, the dODN was present at the site of action in a subattomolar concentration, which is totally insufficient for any antisense effect. For more details on the aODN and dODN syntheses and the RT-PCR analysis of mKv1.1 mRNA in the mouse or rat brain tissues, the reader may refer to our previous papers (Meiri et al, 1997; Ghelardini et al, 1997; Galeotti et al, 1997a,b).

\section{Administration of Antisense Oligonucleotides}

During in vivo experiments to favor cell penetration and to minimize the degradation of the oligonucleotides, phosphorothioate-capped phosphorodiester oligonucleotides associated with an artificial cationic lipid (DOTAP = $N$-(1-(2,3-dioleoyloxy)propyl)- $N, N, N$-trimethylammonium methyl sulfate) proved to be suitable for enhancing cellular uptake (Quattrone et al, 1994). To evaluate the effect of the treatments on the behavioral parameters under investiga- tion, some preliminary experiments were performed. Mice were randomly assigned to an antisense oligonucleotide $(\mathrm{aODN})$, degenerated oligonucleotide $(\mathrm{dODN})$, vector (DOTAP), saline, or naive group. A suitable amount of oligonucleotide was preincubated at $37^{\circ} \mathrm{C}$ for $30 \mathrm{~min}$ with $13 \mu \mathrm{M}$ DOTAP. Each group received a single i.c.v. injection $(5 \mu \mathrm{l} ; 3 \mathrm{nmol}$ of ODN) on days 1,4 , and 7 . All behavioral tests were performed $24 \mathrm{~h}$ after the last i.c.v. injection of aODN or dODN, when the maximal inhibition in the expression of mKv1.1 mRNA in the mouse brain tissue was detected using RT-PCR analysis (Ghelardini et al, 1997; Galeotti et al, 1997a, b).

Having verified that the dODN did not induce any evident modification in the basal behavioral function of mice, as compared to saline- or vector-injected animals (data not shown), dODN-treated animals were used as controls in all experiments.

Some experiments with AMPH or tetraethylammonium $\mathrm{HCl}$ (TEA) on food consumption were also repeated 7 days after the last ODN treatment, to evaluate the recovery of the effect of test compounds when the Kv1.1 channel expression was completely restored (Galeotti et al, 1997a,b).

\section{In Vivo Microdialysis Procedures}

Rats received sodium pentobarbital $(60 \mathrm{mg} / \mathrm{kg}$, i.p.) as surgical anesthesia. An indwelling jugular catheter made of Silastic Medical Grade tubing (Dow Corning, Midland, MI) was implanted. Each rat was then placed in a stereotaxic apparatus for craniotomy. A plastic intracerebral guide cannula (CMA 12, CMA/Microdialysis, Acton, MA) was implanted above the nucleus accumbens $(\mathrm{ML}+1.5 \mathrm{~mm}$ and $\mathrm{AP}+1.6 \mathrm{~mm}$ from bregma, $\mathrm{DV}-6.2 \mathrm{~mm}$ from dura) according to Baumann et al (1994). Animals were housed singly and allowed 7-10 days to recover.

Microdialysis was carried out by following a previously described method (Baumann et al, 1994). In brief, a probe of $2 \mathrm{~mm} \times 0.5 \mathrm{~mm} \quad$ (CMA/12, CMA/Microdialysis) was placed inside the guide cannula, and a polyethylene extension tube (PE-50) was attached to the jugular catheter. Each rat was placed in a bowl, where free movements were allowed. Ringers' solution, containing $147.0 \mathrm{mM} \mathrm{NaCl}$, $4.0 \mathrm{mM} \mathrm{KCl}$, and $1.8 \mathrm{mM} \mathrm{CaCl}_{2}$, was pumped through the probe at $0.5 \mu \mathrm{l} / \mathrm{min}$. Beginning $2-3 \mathrm{~h}$ after insertion of the probe, dialysate samples were collected at 20-min intervals and immediately assayed for DA by HPLC using electrochemical detection. After DA stabilization in dialysate, three baseline samples were collected and DA concentrations were expressed as a percentage of the baseline.

The effects of local infusions of AMPH or COC were assessed in animals pretreated with aODN to Kv1.1 or dODN (controls), given according to the same dosage schedule previously described for mice. AMPH or COC were administered via reverse dialysis, in a single dose of 2 or $5 \mu \mathrm{g}$, respectively, $60 \mathrm{~min}$ after the probe insertion. Samples were collected for $280 \mathrm{~min}$ after the start of the experiments. At the end of the experiments, the location of the probes in the brain was evaluated by means of histological analysis. The data included in this study refer to rats bearing probes correctly placed within the nucleus accumbens. 


\section{Analysis of DA in Dialysate Samples}

Aliquots of the dialysate $(5 \mu \mathrm{l})$ were injected directly into a microbore HPLC column coupled to an amperometric detector. A glass carbon working electrode was set at a potential of $+700 \mathrm{mV}$ relative to an $\mathrm{Ag} / \mathrm{AgCl}$ reference. A mobile phase consisting of $14.2 \mathrm{~g}$ monochloroacetic acid, $6.8 \mathrm{~g} \mathrm{NaOH}, 350 \mathrm{mg}$ sodium octyl sulfate, $80 \mathrm{mg}$ disodium EDTA, $1 \mathrm{ml}$ triethylamine, $6 \% \mathrm{MeOH}, 6 \% \mathrm{CH}_{3} \mathrm{CN}$ per liter of water (final $\mathrm{pH}=5$ ) was pumped at a rate of $60 \mu \mathrm{l} / \mathrm{min}$ with a constant column pressure of 2500-3000 psi. Standard curves of DA, constructed before the injection of dialysate samples, were linear over a wide range of concentrations. The lowest limit of assay sensitivity for DA was $200 \mathrm{fg} / 5 \mu \mathrm{l}$ sample.

\section{Reagents and Drugs}

The oligonucleotides used for the antisense strategy were from Genosys (The Woodlands, USA). DOTAP was from Boheringer-Mannheim (Mannheim, Germany). AMPH sulfate, tyramine hydrochloride (TYR), tetraethylammonium $\mathrm{HCl}$, charybdotoxin (CTX), and gliquidone (GLI) were purchased from the Sigma Chemical Company (St Louis, MO, USA). COC $\mathrm{HCl}$ was supplied by USL 10D (Policlinico di Careggi), Florence; phentermine hydrochloride (PHE) was generously provided by Professor F Mari, Department of Forensic Medicine, Florence; d-fenfluramine (d-FEN) was obtained from S.A.L.A.R.S. (Milan). Chromatographic reagents, buffer salts, and other chemicals used in the microdialysis experiments were obtained from the Sigma Chemical Company (St Louis, MO, USA). The drugs used for the behavioral experiments were dissolved in isotonic $(\mathrm{NaCl} 0.9 \%)$ saline. Drug concentrations were prepared in such a way that the necessary dose could be administered by i.c.v. injection in a volume of $5 \mu \mathrm{l} / \mathrm{mouse}$. Antisense and degenerated oligonucleotides were dissolved in the vector (DOTAP) at least $30 \mathrm{~min}$ before injection.

\section{Statistical Analysis}

All experimental results are given as the mean \pm SEM. An analysis of variance (ANOVA) was used to verify the significance between two means of the behavioral results, and was followed by Fisher's protected least significant difference procedure for post hoc comparison. The results of dose-response experiments of Figure 1 in the dODN and aODN pretreated animals, at each dose of AMPH, were analyzed performing pairwise comparisions with unpaired $t$-tests followed by Bonferroni corrections for multiple
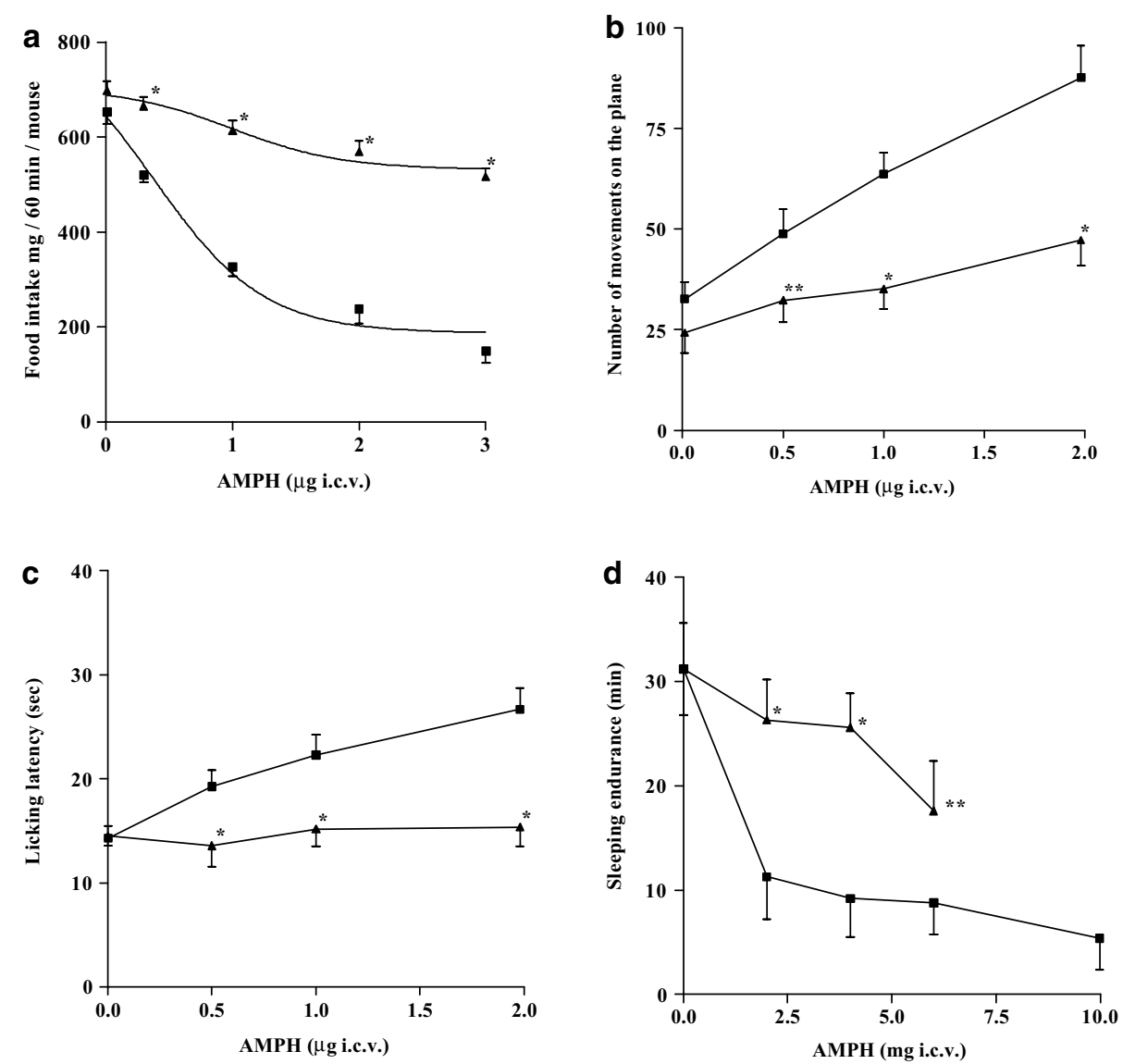

Figure I Effect of the pretreatment with aODN (- $\mathbf{\Delta - )}$ or dODN (- - $)$ to Kvl.I channels ( 3 nmol per single i.c.v. injection at days I, 4, and 7) on the behavioral effects of increasing doses of i.c.v. AMPH. (a) AMPH-induced reduction of food intake in $24 \mathrm{~h}$ fasted mice, $60 \mathrm{~min}$ after food readministration; (b) AMPH-stimulated motor activity, measured in hole board apparatus, 15 min after drug administration; (c) AMPH-increased licking latency in mouse hot-plate test, 15 min after drug administration; (d) AMPH-induced reduction of penthobarbital hypnosis in mice. * $P<0.0$ I in comparison with dODN-pretreated mice taken as controls. ** $P<0.05$ in comparison with $d O D N$-pretreated mice taken as controls. Each point represents the mean \pm SEM of at least 10 mice. 
comparisions. $P$-values of less than 0.05 were considered significant. Data were analyzed using the stat view software for Macintosh (1992). For the microdialysis experiments, the first three samples collected before any experiment were considered as baseline samples; subsequent DA concentrations were expressed as a percentage of the mean of this baseline. For these studies, according to Baumann et al (1994), ANOVA evaluations were performed on the AMPHstimulated percent DA release in aODN-pretreated rats and were then compared with the effects observed in dODNpretreated animals used as controls.

\section{RESULTS}

\section{Single-Dose Treatments}

The central behavioral effects of some compounds endowed with different mechanisms are reported in Table 1. The effect of these compounds in animals pretreated with aODN to Kv1.1 was compared with that observed in mice pretreated with dODN. As detailed in the 'Materials and methods' section, the mice were treated with a single i.c.v. injection of aODN, dODN, or vehicle at days 1,4 , and 7 . Each animal received $3.0 \mathrm{nmol}$ of aODN dissolved in $5 \mu \mathrm{l}$ of vehicle, a dosage previously verified as significantly reducing channel expression in the brain of mice (Galeotti et al, 1997a, b). The results shown in Table 1 and in Figure 1 indicate that the pretreatment with aODN, as well as with dODN, was unable to modify significantly motor behavior, licking latency, endurance of barbiturate-induced sleeping or food intake in animals, as compared to the controls (saline-treated) groups.

The potassium channel blockers TEA, GLI, CTX were administered with a single i.c.v. injection, in doses ranging from 1 to $5 \mu \mathrm{g} / 5 \mu \mathrm{l}$ of vehicle, a dosage regimen previously verified as being effective in inducing anorectic effects (Banchelli et al, 2001; Pirisino et al, 2001). It was found that, at the dose used, these compounds were without effect in modifying all the behavioral functions of mice with the exclusion of food intake. In mice that had fasted for $12 \mathrm{~h}$ they significantly reduced food consumption, as observed after $60 \mathrm{~min}$ from the administration of compound. As shown in Table 1, the aODN (but not the dODN) almost completely suppressed the anorectic effect of $5 \mu \mathrm{g}$ of TEA, while it was completely ineffective in antagonizing the similar anorectic effect of $5 \mu \mathrm{g}$ GLI or $1 \mu \mathrm{g}$ CTX.

Conversely, AMPH and the other chemically related phenylethylamines TYR or PHE modified all the behavioral responses of the mice. In accordance with the known pharmacological effects of AMPHs, a significant analgesic effect, a reduction in barbiturate-induced sleeping and in food intake or hypermotility was observed when $2 \mu \mathrm{g}$ of AMPH or $3 \mu \mathrm{g}$ of TYR or PHE was administered i.c.v. to the mice.

A similar pattern of central pharmacological activity was observed for COC. However, in contrast to the results obtained with AMPH, the aODN pretreatment was completely ineffective in antagonizing the central response induced by COC. A lack of effect of aODN pretreatments was also observed for the anorectic effects of d-FEN.

\section{AMPH Dose-Response Curves}

These experiments were performed in order to better evaluate the role of Kv1.1 expression in the behavioral effects of an increasing AMPH dosage regimen. We had previously verified that the ODNs or vehicle pretreatments ( $3.0 \mathrm{nmol} / 5 \mu \mathrm{l} / \mathrm{mouse}$ i.c.v.) did not modify the behavioral parameters under investigation as compared to the effect of saline in naive mice (data not shown; see for reference Galeotti et al, 1997a, b). Therefore, we compared the doseresponse curves for AMPH in aODN groups with those in dODN-pretreated animals.

In Figure 1a, the reduction in food consumption induced by $\mathrm{AMPH}$ in $24 \mathrm{~h}$ fasted mice is reported. AMPH ranged from 0.5 to $3.0 \mu \mathrm{g} / \mathrm{mouse}$ i.c.v. and food consumption measured $60 \mathrm{~min}$ after food readministration and drug injection. A clearcut dose relation was found for the hypophagic effect of $\mathrm{AMPH}$, with an approximate $\mathrm{ED}_{50}$ of $2.3 \mu \mathrm{g} /$ mouse. According to what was observed in singledose treatments, the aODN considerably reduced the anorectic effect of AMPH. In the control animals, the

Table I Effect of the aODN Towards KvI.I Pretreatment on the Central Behavioral Effects Induced by AMPH, and other Treatments

\begin{tabular}{|c|c|c|c|c|c|c|c|c|}
\hline \multirow{2}{*}{$\begin{array}{l}\text { Compound } \\
\text { i.c.v. }\end{array}$} & \multicolumn{2}{|c|}{$\begin{array}{l}\text { Hot plate test } \\
\text { licking latency (s) }\end{array}$} & \multicolumn{2}{|c|}{$\begin{array}{l}\text { Sleeping test } \\
\text { endurance } \\
\text { of sleep ( } \mathrm{min})\end{array}$} & \multicolumn{2}{|c|}{$\begin{array}{c}\text { Food intake } \\
\mathrm{mg} / 60 \mathrm{~min} / \mathrm{mouse}\end{array}$} & \multicolumn{2}{|c|}{$\begin{array}{l}\text { Hole board test } \\
\text { no. movements }\end{array}$} \\
\hline & dODN & aODN & dODN & aODN & dODN & aODN & dODN & aODN \\
\hline Saline $5 \mu \mathrm{l}$ & $14.8 \pm 1.5$ & $15.1 \pm 1.7$ & $27.4 \pm 2.8$ & $28.2 \pm 3.1$ & $653 \pm 26$ & $697 \pm 20$ & $32.6 \pm 4.2$ & $24.3 \pm 5.1$ \\
\hline TEA $5 \mu \mathrm{g}$ & $14.4 \pm 0.9$ & NT & $25.8 \pm 3.7$ & $N \bar{T}$ & $381 \pm 16^{\mathrm{a}}$ & $674 \pm 25^{*}$ & $36.8 \pm 5.1$ & $N \bar{T}$ \\
\hline GLI $6 \mu \mathrm{g}$ & $15.1 \pm 1.3$ & NT & $29.4 \pm 4.0$ & NT & $346 \pm 23^{a}$ & $360 \pm 18$ & $30.6 \pm 5.5$ & NT \\
\hline CTX I $\mu \mathrm{g}$ & $13.8 \pm 1.1$ & NT & $26.5 \pm 3.9$ & NT & $228 \pm 36^{a}$ & $251 \pm 32$ & $28.2 \pm 6.4$ & NT \\
\hline $\mathrm{AMPH} 2 \mu \mathrm{g}$ & $26.7 \pm 2.0^{a}$ & $15.4 \pm 1.9 *$ & $9.2 \pm 3.7^{a}$ & $26.3 \pm 3.9 *$ & $238 \pm 31^{a}$ & $569 \pm 22 *$ & $87.6 \pm 8.0^{a}$ & $47.3 \pm 6.3^{*}$ \\
\hline $\mathrm{COC} 10 \mu \mathrm{g}$ & $24.5 \pm 2.1^{\mathrm{a}}$ & $23.9 \pm 1.8$ & $16.3 \pm 3.6^{a}$ & $15.9 \pm 2.8$ & $281 \pm 16^{\mathrm{a}}$ & $265 \pm 13$ & $61.4 \pm 6.5^{\mathrm{a}}$ & $63.8 \pm 7.2$ \\
\hline $\mathrm{d}-\mathrm{FEN} 3 \mu \mathrm{g}$ & $16.7 \pm 1.7$ & $N \bar{T}$ & $29.5 \pm 2.4$ & $30.2 \pm 3.9$ & $343 \pm 21^{a}$ & $362 \pm 22$ & $30.6 \pm 5.1$ & $33.4 \pm 6.5$ \\
\hline TYR $3 \mu \mathrm{g}$ & $21.3 \pm 1.5^{\mathrm{a}}$ & $14.8 \pm 1.5 *$ & $19.5 \pm 5.1^{a}$ & $28.8 \pm 4.8^{*}$ & $311 \pm 20^{a}$ & $587 \pm 17 *$ & $49.5 \pm 7.2^{\mathrm{a}}$ & $31.8 \pm 5.1$ \\
\hline $\mathrm{PHE} 3 \mu \mathrm{g}$ & $22.2 \pm 1.4^{\mathrm{a}}$ & $14.0 \pm 1.7^{*}$ & $21.4 \pm 5.2^{\mathrm{a}}$ & $27.9 \pm 4.5^{*}$ & $209 \pm 22^{\mathrm{a}}$ & $54 I \pm 26 *$ & $40.6 \pm 6.3$ & $N \bar{T}$ \\
\hline
\end{tabular}

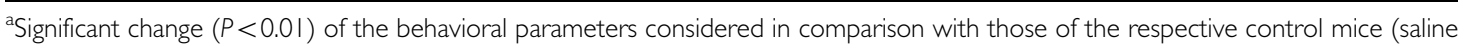
injected). Each value represents the mean \pm SEM of at least 10 animals.

*Significant $(P<0.01)$ in comparison with the anorectic effect of the compound in dODN pretreated animals. NT, not tested. 
highest dose of AMPH $(3 \mu \mathrm{g})$ reduced the food consumption by about $77 \%$ while, in the aODN group the same effect was not statistically significant (about 25\%), as compared to the response obtained with the lower dose $(0.5 \mu \mathrm{g})$ of AMPH. The effect of aODN pretreatment was also evaluated for motor stimulatory activity and for the analgesic effect elicited by increasing the doses of AMPH. The results shown in Figure $1 \mathrm{~b}$ and $\mathrm{c}$ indicate that AMPH induced its effects at a range of doses similar to those used in food intake experiments. In agreement with what was observed for the hypophagic effect of AMPH, the latter behavioral parameters were almost totally abolished by aODN.

Lastly, the ability of aODN to reduce the effect of AMPH was verified in animals in which the inhibition of pentobarbital-induced sleeping was assessed in the presence of increasing doses of AMPH. Again, the aODN pretreatment consistently reduced the effect of AMPH (Figure 1d), with the exclusion of doses exceeding $5 \mu \mathrm{g} /$ mouse, which induced aspecific central toxicity in the animals, as revealed by an evident subcomatose state.

\section{Time Dependence of the aODN Effects}

The aODN injection ( 3 nmol i.c.v. per mouse) prevented the hypophagic response of TEA, AMPH, and other compounds, as shown in Table 1. This antagonistic effect was detected $24 \mathrm{~h}$ after the end of the aODN pretreatment. In contrast 7 days after the last aODN injection, the effect of the oligonucleotide disappeared and the same animals were once again sensitive to the anorectic effect of TEA or AMPH (Figure 2).

\section{Microdialysis Experiments}

The results obtained with the local infusion of $2 \mu \mathrm{g}$ of AMPH or $5 \mu \mathrm{g}$ of COC in freely moving rats are shown in

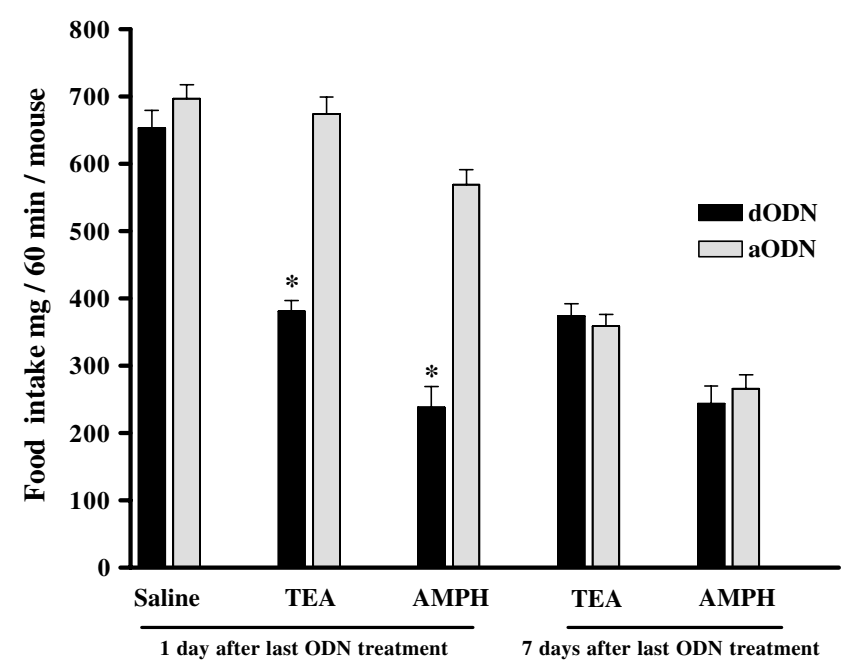

Figure 2 Recovery of the anorectic response of i.c.v.-administered TEA $(5 \mu \mathrm{g})$ or AMPH $(2 \mu \mathrm{g})$ in aODN or dODN (controls) pretreated mice. At 7 days after the last aODN injection, the inhibitory effect of the aODN was completely lost. $* P<0.01$ in comparison with $d O D N$-pretreated mice taken as controls. Each point represents the mean \pm SEM of at least 10 mice.
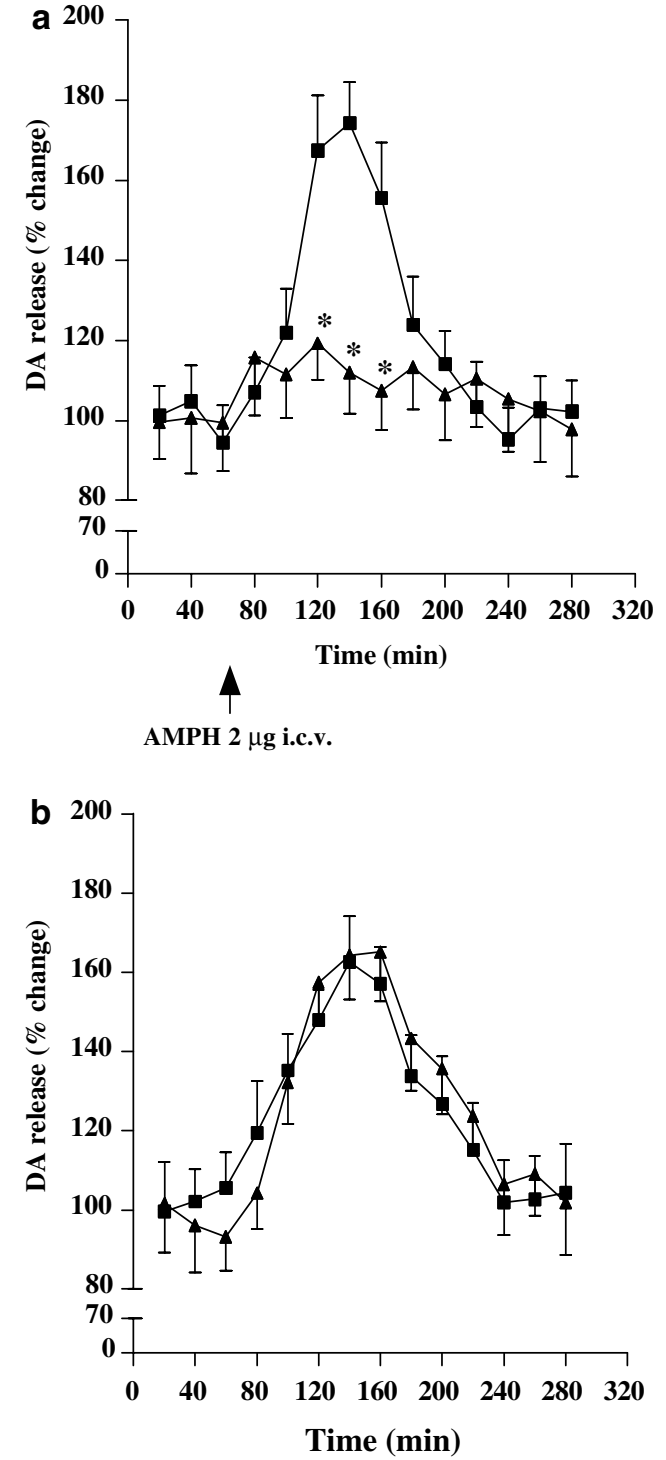

$\operatorname{coc} 5 \mu$ i.c. v.

Figure 3 The effect of aODN or dODN (controls) to Kvl.I channels ( 3 nmol per single i.c.v. injection at days I, 4, and 7) on (a) $2 \mu$ g i.c.v. AMPHinduced or (b) $5 \mu \mathrm{g}$ i.c.v. COC-induced DA release from nucleus accumbens in freely moving rat. $* P<0.01$ in comparison with $d O D N$ pretreated mice taken as controls. Each point represents the mean \pm SEM of five rats.

Figure 3a,b. As described in the Materials and methods section, the percentage change in the DA efflux refers to the release from the nucleus accumbens. At 120-160 min after AMPH infusion, the maximum increase in DA release (50-70\% over the basal values) was observed in control, dODN-pretreated, rats. Similar results were obtained in animals that received local infusion of COC. The most relevant difference in these experiments was that the AMPH-induced increase of DA release was almost completely prevented by the aODN pretreatment, while the same effect induced by COC remained unmodified in aODNpretreated rats. 


\section{DISCUSSION}

The primary aim of this study was to evaluate the effect of an antisense strategy in relation to the Kv1.1 potassium channel subtype on the central effects of AMPH in mice. To this end, the effect of AMPH on food intake, motor behavior, pain threshold, and barbiturate-induced sleeping time was compared to the effect of TEA, ChTX, and GLI, which are known to block different types of potassium channels (Cook and Quast, 1990; Edwards and Weston, 1993).

Molecular cloning has confirmed the presence of various species of at least four subfamilies of voltage-gated potassium channel genes in the brain (Tempel et al, 1988; Stuhmer et al, 1989; Swanson et al, 1990). The Kv1.1 subtype, a voltage-dependent, Shaker-like potassium channel that is widely distributed in the central nervous system (Wang et al, 1994) is able to modulate transmembrane potential and neuronal functions (Hopkins and Tempel, 1992; Bosma et al, 1993; Wang et al, 1994).

We investigated the potassium channel modulating effect of AMPH, TEA, ChTX, GLI, and other reference compounds by assuming that a reduced expression of the Kv1.1 channel subtype should depress those behavioral functions that are presumably linked to this target. As a general feature, aODNs are short synthetic DNA segments complementary to sequences of an mRNA target. By forming DNA/mRNA heteroduplexes, aODNs can transiently inactivate single genes, specifically preventing translation and/or stimulating mRNA cleavage by RNase, and thus downregulating the synthesis of the encoded protein (Kashihara et al, 1998). The administration schedule of aODN anti-Kv1.1 (a single i.c.v. injection on days 1,4 , and 7 before the administration of compounds) was chosen for this study on the basis of previous results obtained in quantitative RT-PCR analysis. These results had shown that this treatment significantly reduced (by more that 60\%) the expression of these channels in the mouse brain (Galeotti et al, 1997a, b).

AMPH, TYR, PHE, d-FEN, and COC were tested, in single-dose experiments, in ODN pretreated animals. The results obtained in terms of food intake and other behavioral tests indicate that a suppression of Kv1.1 channel expression in the mouse brain considerably reduced the central effects of those stimulants that are chemically related to the phenylethylamine skeleton with the exception of d-FEN.

The behavioral effects of AMPH, TYR, PHE, d-FEN, and COC were not completely correlated with the effects obtained with TEA, GLI, or ChTX. At the doses used, these latter compounds reduced food intake without changing the barbiturate-induced sleeping endurance or motor and explorative behavior. Owing to their depolarizing properties, TEA, GLI, or ChTX can increase the central release of different neurotransmitters, including acetylcholine, norepinephrine, DA, and 5-HT (Drukarch et al, 1989; Hu and Fredholm, 1991; Boireau et al, 1991; Schechter, 1997). Considering that, similar to food intake, the other behavioral parameters used in our tests are also regulated by neurons that release different transmitters, including 5HT and DA, into discrete brain areas, the results obtained with these blockers should be regarded as contradictory. To explain these observations, it must be considered that, as previously assessed (Galeotti et al, 1999), higher doses of these compounds induce strong motor activity and seizures in mice, which impairs other behavioral evaluations. These results showed that the food consumption is more sensitive than other central functions to the low doses of the potassium channel blockers used in this work.

On the other hand, since a more extensive analysis of the central stimulatory effects of TEA, ChTX, or GLI would surpass the aim of the present work, the dosage regimen of these compounds - which are capable of modifying behavioral parameters different from food intake-was not investigated further.

In our experiments, only the anorectic effect of TEA was significantly reduced by the aODN pretreatment, while the same activity induced by ChTX or GLI was unaffected. These results clearly demonstrate that a strong reduction in the Kv1.1 channel expression in the mouse brain abolishes the effect of a compound (TEA) which, notwithstanding its nonselective channel blocking properties, presumably acts on this channel subtype as an anorexigenic. Conversely, the failure of the aODN to reduce the central activity of ChTX or GLI indicates that, at least at the doses used, the anorectic effect of these latter compounds seemingly does not involve a modulation of Kv1.1 channels: $\mathrm{Ca}^{2+}$-activated, a different type of voltage-activated or $\mathrm{K}_{\mathrm{ATP}}$ channels are presumably the target for ChTX or GLI effects, respectively.

Dose-response experiments also showed that, differently from TEA, it was not possible to separate the anorectic doses of AMPH from those that elicited analgesic, analeptic, or motor stimulatory effects. This feature made it difficult to better evaluate the specific role of AMPH, particularly in analgesia and food consumption experiments, which can be indirectly affected by changes in arousal and motor behavior. Several studies provide support for this point. It has in fact been suggested that AMPH-induced reduction of sleeping time, anorexia, hyperlocomotion, or analgesia are distinct behavioral effects of this compound (Samanin and Garattini, 1993; Altier and Stewart, 1998; Inui, 2000). In any case, the observation that aODN suppresses all the behavioral effects of AMPH in an apparently noncompetitive manner indicates that the central activity of this compound is closely dependent on the number of functionally active Kv1.1 channels actually expressed in the brain. As shown in Figure 2, the complete recovery of the central anorectic effects of AMPH and TEA 7 days after the last i.c.v. injection of aODN further supports these conclusions. These data indicate that the knockdown of Kv1.1 channels produced by the aODN pretreatment is reversible. Furthermore, they indicate that, 7 days after the end of the last aODN treatment, there is a complete recovery of the channel functionality, suggesting a lack of toxicity and neural damage after this aODN treatment.

It is well known that $\mathrm{AMPH}$, or COC, elicits its locomotory stimulatory effect mainly by increasing the extracellular concentration of DA in the mesolimbic system: the nucleus accumbens is an important target for these effects (Kalivas et al, 1993; Giros et al, 1996; Bardo, 1998). Other evidence also indicates that 5-HT and glutamate transmission contribute to the central activity of these stimulants (Chiamulera et al, 2001; Simansky, 1996).

AMPH and COC also have analgesic properties, which probably involve a stimulation of $\mathrm{D}_{2}$ inhibitory presynaptic 
receptors (Schuelke et al, 1996; Altier and Stewart, 1998). The observation that AMPH, like morphine, can increase extracellular DA in the nucleus accumbens, the ventral tegmental area and the amygdala brain areas known to be involved in antinociception, is consistent with this view (Morgan and Franklin, 1990; Schuelke et al, 1996).

Potassium channels modulate the drug-induced antinociception. For example, $\mathrm{K}_{\mathrm{ATP}}$ openers potentiate morphine or tricyclic antidepressant-induced analgesia in mice, while blockers which are devoid of analgesic properties do not seem to modify significantly morphine antinociception (Ocana and Baeyens, 1993; Ocana et al, 1996; Galeotti et $a l, 2001)$. These observations are in good agreement with the absence of analgesic effects of TEA, ChTX, and GLI as observed in the present work. On the contrary, AMPH, TYR, PHE, and COC all elicited antinociceptive effects in the hotplate test, significantly increasing the licking latency in mice. The most relevant difference between these compounds was that the aODN pretreatment abolished the analgesic effect of AMPH-like derivatives, but not that of COC. The lack of effect of aODN pretreatment was also verified for all the behavioral tests using COC that were performed on mice.

Notwithstanding the fact that AMPH and COC both display indirect dopaminergic/serotoninergic properties, it is well known that these compounds act with different mechanisms in increasing the extracellular concentration of neuromediators. COC is known to be a neuronal uptake 1 blocker, whereas AMPH, PHE, and TYR are classified as substrate-type releasers (Sonders et al, 1997; Wayment et al, 1998). To explain this difference, it has been postulated that the latter amines increase exocytosis by promoting a reverse transport from synaptic vesicles to cytosol (Sulzer and Rayport, 1990; Sulzer et al, 1995). It has also been suggested that AMPH and other substrate-type releasers induce exocytosis by elevating the intragranular $\mathrm{pH}$, thus disrupting the association of catecholamines with $\mathrm{Ca}^{2+}$, ATP, and vesicular proteins (Mundorf et al, 1999).

Recently, some electrophysiological results have focused on the possibility that AMPH may directly block the transient outward $\mathrm{K}^{+}$current responsible for the action potential repolarization in cardiac myocytes (Casis et al, $2000)$. Other investigations point to the delayed rectifier $\mathrm{K}^{+}$ channels blocking properties in order to explain the anorectic effect of d-FEN, a releasing agent that is structurally related to AMPH ( $\mathrm{Hu}$ et al, 1998). Owing to these properties, AMPH and d-FEN are suspected of facilitating the appearance of cardiovascular or pulmonary toxicity in abusers.

The present results are reasonably in agreement with the possibility that AMPH also acts as a blocker of voltageoperated potassium channels in central compartments, in turn inducing depolarization, $\mathrm{Ca}^{2+}$ elevation, and neuronal exocytosis. The observation that aODN pretreatment substantially reduces the AMPH-induced DA efflux in rat microdialysis experiments, while also impairing the central activity of TYR and PHE (both substrate-type releasers that share the phenylaethylamine skeleton with AMPH), reinforces the view that Shaker-like Kv1.1 subtypes are primarily involved in these effects. Conversely, the failure of the aODN to reduce the anorectic effect of d-FEN could be explained with the observation that this preferential serotoninergic agent (Baumann et al, 2000) may block channel subtypes different from Kv1.1 (such as Kv1.5 or $\mathrm{Kv} 2.1$ ), as proposed for the activity of this compound in rat taste cells (Hu et al, 1998).

Finally, the lack of an effect of aODN in counteracting the stimulant activity of COC could be attributed to the ability of this compound to increase, at least at the dosage used in these experiments, the extracellular DA by means of an action mechanism different from that of AMPH. This view seems to be in agreement with the results of microdialysis experiments, showing that aODN pretreatments completely prevent DA efflux induced in rats by $2 \mu$ g i.c.v. AMPH, but not by $5 \mu \mathrm{g}$ i.c.v. COC (Figure 3a,b). These results are also consistent with the observation that $\mathrm{K}_{\mathrm{ATP}}$ openers attenuate the central effects of AMPH, but not those of COC (Rosenzweig-Lipson et al, 1997), and further suggest that the exocytotic process stimulated in neurons by indirectly acting, dopaminergic substrate-type releasers could be triggered early by a reduction in Shaker-like Kv1.1 potassium channel conductance.

\section{REFERENCES}

Adzu B, Amos S, Dzarma S, Wambebe C, Gamaniel K (2002). Effect of Zizyphus spine Christi Willd aqueous extract on the central nervous system in mice. J Ethnopharmacol 79: 13-16.

Altier N, Stewart J (1998). Dopamine receptor antagonists in the nucleus accumbens attenuate analgesia induced by ventral tegmental area substance $\mathrm{P}$ or morphine and by nucleus accumbens amphetamine. J Pharmacol Exp Ther 285: 208-215.

Banchelli G, Ghelardini C, Raimondi L, Galeotti N, Pirisino R (2001). Selective inhibition of amine oxidases differently potentiate the hypophagic effect of benzylamine in mice. Eur J Pharmacol 413: 91-99.

Bardo MT (1998). Neuropharmacological mechanisms of drug reward: beyond dopamine in the nucleus accumbens. Crit Rev Neurobiol 12: 37-67.

Baumann MH, Ayestas MA, Dersch CM, Brockington A, Rice KC, Rhothman RB (2000). Effects of phentermine and fenfluramine on extracellular dopamine and serotonin in rat nucleus accumbens: therapeutic implications. Synapse 36: 102-113.

Boireau A, Richard F, Olivier V, Aubenau M, Miquet JM, Dubedat $P$ et al (1991). Differential effects of potassium channel blockers on dopamine release from striatal slices. J Pharm Pharmacol 43: 798-801.

Bosma MM, Alen ML, Martin TM, Tempel BL (1993). PKAdependent regulation of $\mathrm{mKv} 1.1$, a mouse Shaker-like potassium channel gene, when expressed in CHO cells. J Neurosci 13: 52425250.

Casis O, Espina L, Gallego M (2000). Effects of amphetamine on calcium and potassium currents in rat heart. $J$ Cardiovasc Pharmacol 36: 390-395.

Chandy KG, Williams CB, Spencer RH, Aguilar BA, Ghanshani S, Tempel BL et al (1990). A family of three mouse potassium channel genes with intronless coding regions. Science 247: 973975.

Chiamulera C, Epping-Jordan MP, Zocchi A, Marconl C, Cottiny C, Tacconi $S$ et al (2001). Reinforcing and locomotor stimulant effects of cocaine are absent in mGIuRS null mutant mice. Nat Neurosci 4: 873-874.

Cook NS, Quast U (1990). Potassium channel pharmacology. In: Cook NS (ed). Potassium Channels: Structure, Classification, Function and Therapeutic Potential. Ellis Horwood: Chichester. pp 181-255. 
Dawson LA, Routledge C (1995). Differential effects of potassium channel blockers on extracellular concentrations of dopamine and 5-HT in the striatum of conscious rats. Br J Pharmacol 116: 3260-3264.

Drukarch B, Kits KS, Leysen JFE, Shepens E, Stoof JC (1989). Restricted usefulness of tehraethylammonium and 4-aminopyridine for the 1 characterization of receptor-operated $\mathrm{K}^{+}$ channels. Br J Pharmacol 98: 113-118.

Edwards G, Weston AH (1993). The pharmacology of ATPsensitive potassium channels. Ann Rev Pharmacol Toxicol 33: 597-637.

Frantz KJ, Hansson KJ, Stouffer DG, Parsons LH (2002). 5- $\mathrm{HT}_{6}$ receptor antagonism potentiates the behavioral and neurochemical effects of amphetamine but not cocaine. Neuropharmacology 42: $170-180$.

Galeotti N, Ghelardini C, Bartolini A (2001). Involvement of potassium channels in amitriptyline and clomipramine analgesia. Neuropharmacology 40: 75-84.

Galeotti N, Ghelardini C, Caldari B, Bartolini A (1999). Effect of potassium channel modulators in mouse forced swimming test. Br J Pharmacol 126: 1653-1659.

Galeotti N, Ghelardini C, Capaccioli S, Quattrone A, Nicolin A, Bartolini A (1997a). Blockade of clomipramine and amitriptyline analgesia by an antisense oligonucleotide to mKv1.1, a mouse Shaker-like $\mathrm{K}^{+}$channel. Eur J Pharmacol 330: 15-25.

Galeotti N, Ghelardini C, Papucci L, Capaccioli S, Quattrone A, Bartolini A (1997b). An antisense oligonucleotide on the mouse shaker-like potassium channel Kv1.1 gene prevents antinociception induced by morphine and baclofen. J Pharmacol Exp Ther 281: 941-949.

Ghelardini C, Galeotti N, Pecori VA, Capaccioli S, Quattrone A, Bartolini A (1997). Effect of $\mathrm{K}^{+}$channel modulation on mouse feeding behaviour. Eur J Pharmacol 329: 1-8.

Giros B, Jaber M, Jones SR, Wightman M, Caron MG (1996). Hyperlocomotion and indifference to cocaine and amphetamine in mice lacking the dopamine transporter. Nature 379: 606-612.

Haley TJ, Mccormick WG (1957). Pharmacological effects produced by intracerebral injection of drugs in the conscious mouse. Br J Pharmacol Chemother 12: 12-15.

Hoffman BB (2001). Chatecolamines, symphatomimetic drugs, and adrenergic receptor antagonists. In: Hardman JG, Limbird LE, (ed), Gilman AG (c-ed). Goodman \& Gilman's The Pharmacological Basis of Therapeutics, 10th edn. McGraw-Hill Companies, Inc.: New York. pp 216-237.

Hopkins WF, Tempel BL (1992). Members of a mouse subfamily of genes encoding voltage-gated potassium channel subunits form heteromultimers when co-expressed in Xenopus oocytes. Soc Neurosci Abstr 18: 1093.

$\mathrm{Hu}$ P, Fredholm BB (1991). 4-Aminopyridine-induced increase in basal and stimulation-evoked $[3 \mathrm{H}]-\mathrm{NA}$ release in slices from rat hippocampus: $\mathrm{Ca}^{2+}$ sensitivity and presynaptic control. $\mathrm{Br} \mathrm{J}$ Pharmacol 102: 764-768.

Hu SH, Wang S, Gibson J, Gilbertson TA (1998). Inhibition of delayed rectifier $\mathrm{K}^{+}$channels by dexfenfluramine (Redux). $J$ Pharmacol Exp Ther 287: 480-486.

Kalivas PW, Churchill L, Klitenick MA (1993). The circuitry mediating the translation of motivational stimuli into adaptive motor responses. In: Kalivas PW, Barnes CD (eds). Limbic Motor Circuits and Neuropsychiatry. CRC Press: Boca Raton, FL. pp 237-287.

Kashihara N, Maeshima Y, Makino H (1998). Antisense oligonucleotides. Exp Nephrol 6: 84-88.

Inui A (2000). Transgenic approach to the study of body weight regulation. Pharmacol Rev 52: 35-61.

Leibowitz SF (1989). Hypothalamic neuropeptide Y, galanin, and amines: concepts of coexistence in relation to feeding behavior. Ann NY Acad Sci 575: 221-233.
Meiri N, Ghelardini C, Tesco G, Galeotti N, Dahl D, Tomsic D et al (1997). Reversible antisense inhibition of Shaker-like Kv1.1 potassium channel expression impairs associative memory in mouse and rat. Proc Natl Acad Sci USA 94: 44304434.

Morgan MJ, Franklin KBJ (1990). 6-Hydroxydopamine lesions of the ventral tegmentum abolish $(+)$-amphetamine and morphine analgesia in the formalin test but not the tail flick test. Brain Res 619: 144-149.

Mundorf ML, Hochstetler SE, Wightman RM (1999). Amine weak bases disrupt vesicular storage and promote exocytosis in chromaffin cells. J Neurochem 73: 2397-2405.

O'callaghan JP, Holtzman SG (1975). Quantification of the analgesic activity of narcotic antagonists by a modified hotplate procedure. J Pharmacol Exp Ther 192: 497-505.

Ocana M, Baeyens Jm (1993). Differential effect of $\mathrm{K}^{+}$channel blockers on antinociception induced by $\alpha 2$-adrenoceptor, GABA $\mathrm{B}$ and k-opioid receptor agonists. Br J Pharmacol 110: 10491054.

Ocana M, Barrios M, Baeyens JM (1996). Cromakalim differentially enhances antinociception induced by agonists of alpha2 adrenoceptors, $y$-aminobutyric acid $\mathrm{B}, \mathrm{mu}$ and kappa opioid receptors. J Pharmacol Exp Ther 276: 1136-1142.

Parada MA, Hernandez L, Shwartz D, Hoebel BG (1988). Hypothalamic infusions of amphetamine increase serotonin, dopamine and norepinephrine. Physiol Behav 44: 607-610.

Pirisino R, Ghelardini C, Banchelli G, Galeotti N, Raimondi L (2001). Methylamine and benzylamine induced hypophagia in mice: modulation by semicarbazide-sensitive benzylamine oxidase inhibitors and aODN towards Kv1.1 channels. $\mathrm{Br} J$ Pharmacol 134: 880-886.

Quattrone A, Papucci L, Schiavone N, Mini E, Capaccioli S (1994). Intracellular enhancement of intact antisense oligonucleotide steady-state levels by cationic lipids. Anticancer Drug Des 9: 549_ 553.

Rosenzweig-Lipson S, Thomas S, Barrett JE (1997). Attenuation of the locomotor activating effects of d-amphetamine, cocaine, and scopolamine by potassium channel modulators. Prog Neuro Psycopharmacol Biol Psychiatry 21: 869-872.

Samanin R, Garattini S (1993). Neurochemical mechanism of action of anorectic drugs. Pharmacol Toxicol 73: 63-68.

Schechter LE (1997). The potassium channel blockers 4-aminopyridine and tetraethylammonium increase the spontaneous basal release of [3H] 5-hydroxytryptamine in rat hippocampal slices. $J$ Pharmacol Exp Ther 82: 262-270.

Schuelke GS, Cass Terry L, Powers RH, James Rice J, Madden JA (1996). Cocaine analgesia: an in vivo structure-activity study. Phamacol Biochem Behav 53: 133-140.

Simansky KJ (1996). Serotonergic control of the organization of feeding and satiety. Behav Brain Res 73: 37-42.

Sonders MS, Zhu SJ, Zahnhiser NR, Kavanaugh MP, Amara SG (1997). Multiple ionic conductances of the human dopamine transporter: actions of dopamine and psychostímulants. $J$ Neurosci 17: 960-974.

Stuhmer W, Ruppersberg JP, Schroter KH, Saemann B, Stocker M, Giese KP et al (1989). Molecular basis of functional diversity of voltage-gated potassium channels in mammalian brain. EMBO J 8: 3235-3244.

Sulzer D, Chen TK, Lau YY, Kristensen H, Rayport S, Ewing A (1995). Amphetamine redistributes dopamine from synaptic vesicles to the cytosol and promotes reverse transport. J Neurosci 15: 4102-4108.

Sulzer D, Rayport S (1990). Amphetamine and other psychostimulants reduce $\mathrm{pH}$ gradient in midbrain dopaminergic neurons and chromaffin granules: mechanism of action. Neuron 5: 797808.

Swanson R, Marshall J, Smith JS, Williams JB, Boyle MB, Folander $\mathrm{K}$ et al (1990). Cloning and expression of cDNA and genomic 
clones encoding three delayed rectifier potassium channels in rat brain. Neuron 4: 929-939.

Tempel BL, Jan YN, Yan LY (1988). Cloning of a probable potassium channel gene from the mouse brain. Nature 332: 837839.

Wang H, Kunkel DD, Schwartzkroin PA, Tempel BL (1994). Localization of $\mathrm{Kv1.1}$ and $\mathrm{Kv1.2}$, two $\mathrm{K}$ channel proteins, to synaptic terminals, somata, and dendrites in the mouse brain. $J$ Neurosci 14: 4588-4599.

Wayment H, Meiergerd SM, Schenk JO (1998). Relationship between the catechol substrate binding site and amphetamine, cocaine, and mazindol binding sites in a kinetic model of the striatal transporter of dopamine in vitro. J Neurochem 70: 9411949. 